\title{
NOTAS (PROVISÓRIAS) SOBRE A RELAÇÃO MARX-HEGEL
}

Jadir Antunes ${ }^{1}$

Resumo: Nosso artigo pretende analisar, nas suas linhas mais gerais, a complexa e rica relação entre os sistemas dialéticos de Marx e Hegel. Em nosso ponto de vista, a única relação possível entre estes dois sistemas é a da crítica radical - da exclusão e negação de um pelo outro. Nosso ponto de vista é o da irredutibilidade de um sistema pelo outro, é o da impossibilidade de se comparar e encontrar em Marx similaridades, homologias e acordos com o sistema de Hegel. Inicialmente, analisaremos os diferentes estudos acerca da relação Marx-Hegel e da diferença entre ambos os sistemas para, em seguida, analisar estes sistemas através de seus dois conceitos mais importantes e fundamentais, de absoluto para Hegel e de crise para Marx, mostrando que ambos os conceitos estruturam-se a partir de perspectivas dialéticas radicalmente distintas e opostas entre si.

Palavras-chave: Marx; Hegel; dialética.

Abstract: Our article intends to analyze, in its most general lines, the complex and rich relationship between Hegel's and Marx's dialectical systems. According to our view, the only possible relationship between these two systems is the radical critique - the exclusion and denial of one another. Our viewpoint is the irreducibility of one system to the other, the impossibility of comparing and finding in Marx similarities, homologies and agreements with the Hegelian system. Initially we analyze the different studies on the Marx-Hegel relationship and the difference between both systems. After that, we analyze these systems through its two most important and fundamental concepts, absolute for Hegel and crisis for Marx, showing that both concepts are structured from radically different and opposite dialectical perspectives.

Keywords: Marx; Hegel; dialectic.

Nosso artigo pretende analisar, nas suas linhas mais gerais, a complexa e rica relação entre os sistemas dialéticos de Marx e Hegel. Em nosso ponto de vista, a única relação possível entre estes dois sistemas é a da crítica radical - da exclusão e negação de um pelo outro. Nosso ponto de vista é o da irredutibilidade de um sistema pelo outro, é o da impossibilidade de se comparar e encontrar em Marx similaridades, homologias e acordos com o sistema de Hegel.

Inicialmente analisaremos os diferentes estudos acerca da relação Marx-Hegel e da diferença entre ambos os sistemas para, em seguida, analisar estes sistemas através de seus dois conceitos mais importantes e fundamentais, de absoluto para Hegel e de crise para Marx, mostrando que ambos os conceitos estruturam-se a partir de perspectivas dialéticas radicalmente distintas e opostas entre si.

\footnotetext{
${ }^{1}$ Possui Graduação em Economia pela Universidade Estadual do Oeste do Paraná (1999), Mestrado em Filosofia (2002) e Doutorado em Filosofia (2005) pela Unicamp - Universidade Estadual de Campinas SP. É Professor Associado da Unioeste - Universidade Estadual do Oeste do Paraná - na Graduação e no Programa de Mestrado e Doutorado em Filosofia. Tem experiência na área de Ética e Filosofia Política, atuando principalmente em Filosofia Política Moderna e Filosofia Marxista. Email: jdiant@yahoo.com.br. Site pessoal: https://jadirantunes.wordpress.com/.
} 


\section{Introdução}

Sabemos que Marx, apesar de ter declarado abertamente seu rompimento com Hegel e o idealismo alemão a partir de 1845 - data da redação de $A$ ideologia alemã -, nunca se separou radicalmente dos ensinamentos de Hegel, mesmo em sua chamada fase de maturidade a fase de $O$ Capital e das obras que o completam como os Grundrisse, Contribuição à crítica da economia política e Teorias sobre a mais-valia. Neste sentido, as obras $O$ Capital e os Grundrisse parecem possuir, à primeira vista, uma estrutura expositiva muito semelhante, se não igual, à estrutura expositiva da Ciência da Lógica.

Lênin - entre 1914 e 1915 - foi um dos primeiros marxistas a compreender a necessidade de se estudar a estrutura expositiva da Ciência da Lógica para se compreender a estrutura de $O$ Capital de Marx. O motivo para este estudo teria sido seu descontentamento com as posições políticas da chamada II Internacional Socialista dirigida por Kautsky e Bernstein e o apoio destes à entrada da Alemanha na I Guerra Mundial. Lênin acreditava que a posição desastrosa de apoiar a guerra deveria ser explicada pela má formação filosófica dos socialistas alemães. Para ele, o estudo mais detalhado da Ciência da Lógica e da sua relação com $O$ Capital poderia fornecer ao movimento socialista do começo do século XX um caminho mais rico política e filosoficamente.

Um segundo intelectual a tentar mostrar a relação estrutural entre $O$ Capital e a

Ciência da Lógica foi Roman Rosdolsky em sua obra editada nos anos 50 chamada Gênese e estrutura de O Capital de Marx: estudos sobre os Grundrisse. Rosdolsky foi um dos primeiros eruditos a ter acesso aos Grundrisse logo após sua edição nos anos 30 pelo Instituto MarxEngels de Moscou. Rosdoslsky diz ter visto nos Grundrisse a chave para, finalmente, se desvendar os mistérios mais importantes de $O$ Capital e da relação de Marx com Hegel, especialmente com a Ciência da Lógica e o método de exposição.

Nas palavras de Rosdolsky a edição dos Grundrisse poria fim às leituras superficiais de Marx e de O Capital. "Cabe assinalar aos Grundrisse como uma grande remissão a Hegel e em especial a sua Ciência da Lógica, demonstrando a forma radicalmente materialista em que se reverteu a Hegel neste caso ${ }^{, 2}$, diz ele.

Hiroshi Uchida, já nos anos 80, seguindo o caminho aberto por Rosdolsky, é outro intelectual que concorda com a relação de identidade entre os Grundrisse e $O$ Capital e a Ciência da Lógica. Em sua obra Marx's Grundrisse and Hegel's Logic (USA: Routledge, 1988), Uchida procurou avançar nas descobertas de Rosdolsky. "Este livro [diz ele no Prefácio] concorda com a relação entre os Grundrisse de Karl Marx e a Lógica de Hegel. Eu tento provar que a relação é mais profunda e mais sistemática do que foi até aqui apreciada".

\footnotetext{
${ }^{2}$ Roman Rosdolsky: Génesis y Estructura de El Capital de Marx: estudios sobre los Grundrisse. Quinta Edição. México: Siglo Veintiuno Editores, 1986, pp. 13 e 14.

\begin{tabular}{|c|c|c|c|}
\hline Qevista Dialectus & Ano 3 & n. 8 & Janeiro - Agosto 2016 \\
\hline
\end{tabular}
}


Segundo Uchida, os temas dos Grundrisse podem ser sumariados do seguinte

modo:

Para Marx, a Lógica de Hegel é a 'moeda do espirito' [the money of the spirit], o especulativo 'valor-pensamento' [thought-value] do homem e da natureza'. Isto significa que na sociedade burguesa 'homem' e natureza, e corpo e mente, estão separados e reconectados através da relação de troca privada. Sua relação está alienada das pessoas que formam esta relação, que está mediada pelo valor. Eles tornam-se 'sujeitos-valor' [value-subjects], e aqueles que possuem valor suficiente governam a sociedade. A Lógica de fato descreve o sujeito-valor [value-subject] abstratamente (Prefácio). ${ }^{3}$

Christopher Arthur, já nos anos 90, é outro autor que pode ser incluído na tradição de leitura de $O$ Capital pelo caminho da Ciência da Lógica. É sabido que Marx começa a crítica em $O$ Capital a partir da noção de circulação mercantil simples. Esta forma de circulação se caracteriza pelo fato de que sua fórmula M-D-M se diferencia radicalmente da forma da circulação capitalista D-M-D'.

Arthur critica a tradição historicista - que teria, segundo ele, origem em Engels que concebe erroneamente que na primeira seção do Livro Primeiro de $O$ Capital, Marx estaria tratando de descrever o modo de circulação de uma determinada sociedade historicamente anterior à sociedade capitalista ${ }^{4}$. Arthur, partindo das lições da Ciência da Lógica, critica esta concepção e mostra que ali Marx estaria tratando, sim, da forma aparente e ilusória da sociedade capitalista e de seu momento mais externo e imediato de manifestação. Momento que seria negado na medida em que a exposição dialética avançasse na direção de seus pressupostos.

Mark Meaney, intelectual norte americano, é outro que segue esta mesma linha de interpretar O Capital pelo caminho da Ciência da Lógica. Cito aqui, parte de sua palestra proferida na França apresentando sua obra Capital as Organic Unity: The Role of Hegel's Science of Logic in Marx's Grundrisse ${ }^{5}$. 3 Vide Hiroshi Uchida: Marx's Grundrisse and Hegel's Logic. USA: Routledge 1988 - Preface.
Disponível em http://www.marxists.org/subject/japan/uchida/index.htm.
${ }^{4}$ Christopher J. Arthur: The Myth of 'Simple Commodity Production'. In: Marx Myths and Legends,
2005. Disponível no website http://marxmyths.org. Questões sobre o problema da exposição em Marx e
da relação com Hegel podem ainda ser encontradas nas seguintes obras deste autor: 1) The New Dialectic
and Marx's Capital. Boston: Brill, 2004. 2) Dialectics of Labour: Marx and his Relation to Hegel.
Oxford: Basil Blackwell, 1986. 3) 'Capital et méthode' in Dialectiques aujourd'hui, eds B. Ollman et L.
Seve, Éditions Syllepse et Espaces Marx, Paris 2006 (pp. 43-50). 4) 'Il Capitale di Marx e la Logica di
Hegel' in Sulle Tracce di un Fantasma: L'Opera di Karl Marx tra Filologia e Filosofia a cura di
Marcello Musto, manifestolibri, Roma 2005. 5) 'Hegel's Logic and Marx's Capital', in Fred Moseley
(ed.) Marx's Method in Capital: A Reexamination. Humanities Press, Atlantic Highlands N.J., 1993. 6)
'Dialectic of the Value-Form', in D. Elson (ed.) Value: The Representation of Labour in Capitalism.
C.S.E. Books, London; and Humanities Press, Atlantic Highlands, N.J., 1979.
5.USA: Kluwer Academic Publishers, 2003). Cito aqui sua palestra proferida no Congrès Marx
international IV organizado pela Revista Actuel Marx de Paris entre os dias 28 de setembro e 2 de outubro

\begin{tabular}{|l|l|l|l|l|}
\hline Qovista QDialectus & Ano 3 & n. 8 & Janeiro - Agosto 2016 & p. 60-76 \\
\hline
\end{tabular}


Diz ele que:

No capítulo 2 de meu livro, demonstrei que a relação entre categorias econômicas na exposição da 'circulação simples' de Marx reflete precisamente a forma lógica do ser [the logical form of being], ou a relação entre categorias como um 'mútuo transpassamento' [passing over into], como um 'desaparecimento de um no outro' [vanishing of one into the other]. Marx começa sua exposição do capital como uma unidade orgânica na precisa maneira que Hegel indica como logicamente própria. Ele começa com as formas imediatas de existência do capital como elas superficialmente aparecem. Tais formas de existência são coisas, ou objetos dos sentidos, e, como tais, elas estão relacionadas externamente... Marx começa pela circulação simples, ou do capital como ele aparece, com a emergência da moeda [money] como um representante material e universal da riqueza.

Como podemos ver, Meaney critica a interpretação historicista do começo em $O$ Capital para relacionar este começo com a Ciência da Lógica. Meaney conclui a apresentação de sua obra aos franceses dizendo que:

Consequentemente, eu mostro como os Grundrisse podem ser divididos em três seções, ou estágios, baseados numa forma lógica. $O$ primeiro, mais abstrato estágio da exposição do capital em geral está estruturado de acordo com a lógica do ser [logic of being]; o segundo de acordo com a lógica da essência [logic of essence]; enquanto o terceiro, o mais concreto estágio está estruturado de acordo com a lógica do conceito [logic of concept]. Cada seção, ou estágio na exposição, está distinguida de outros baseada na lógica peculiar [peculiar logic] usada na exposição da matéria particular tratada na seção.

\section{Marx e a herança hegeliana}

Na fase de redação dos Grundrisse Marx preocupava-se com a elaboração de um método de exposição correto que, à maneira de Hegel, partisse do abstrato e se elevasse em direção do concreto como concreto pensado pelo pensamento. Dizia Marx que parecia ser correto começar a exposição pelo real e concreto, mas, que este começo, visto mais de perto, deveria ser considerado falso, pois se começássemos pela população, como geralmente se começava entre os economistas ingleses, chegar-se-ia inevitavelmente à categorias mais simples e genéricas como a categoria valor. O método correto de exposição, segundo Marx, deveria, por isso, partir destas categorias mais simples e abstratas e elevar-se lentamente, através de uma série de mediações, até o concreto como uma rica totalidade organizada pelo pensamento, ainda que este concreto correspondesse ao real situado fora do pensamento. Ainda que tanto as

de 2004 na França. A palestra pode ser encontrada no endereço: http://netx.uparis10.fr/actuelmarx/m4meaney.htm.

\begin{tabular}{|l|l|l|l|l|}
\hline Qovista Dialectus & Ano 3 & n. 8 & Janeiro - Agosto 2016 & p. 60-76 \\
\hline
\end{tabular}


categorias mais simples como as mais complexas existam na realidade "o método que consiste em elevar-se do abstrato ao concreto é para o pensamento somente a maneira de apropriar-se do concreto, de reproduzi-lo como um concreto espiritual”, dizia Marx.

Marx chegou a confessar a Engels a aplicação da Lógica de Hegel na redação dos Grundrisse numa carta escrita em torno de 16 de janeiro de 1858. "Em meu método de trabalho, dizia ele, tem me prestado um grande serviço o fato de ter folheado acidentalmente a Lógica de Hegel, que ganhei de presente de Freiligrath e que originalmente pertencera a Bakunin" "7. A relação entre o método de Marx e o de Hegel exposto na Ciência da Lógica parece ser, por isso, evidente - ainda que ambos os métodos não se identifiquem diretamente e o método de Marx deva ser concebido como a inversão do de Hegel.

No Posfácio da segunda edição de O Capital (1873), Marx comentava que em sua juventude criticara o lado mistificador da dialética hegeliana, mas que agora, trinta anos depois, diante de medíocres que tratavam Hegel como cachorro morto, era necessário recuperar a dialética de Hegel. Marx confessava nesse prefácio que no capítulo sobre o valor - o capítulo introdutório de $O$ Capital - andara empregando em diversas passagens os modos e expressões peculiares de Hegel. O modo mistificador da dialética de Hegel não o impediu de empregá-la conscientemente. Mas para isso, seria necessário inverte-la para que ela mesma revelasse seu lado racional. Como diz Marx "é necessário inverte-la [a dialética de Hegel], para descobriro cerne racional dentro do invólucro místico", ${ }^{\text {. }}$

Marx acusava a dialética de Hegel de ser conservadora, porque ela, em sua forma mistificada "parecia tornar sublime o existente". . A dialética em sua configuração racional, porém, a dialética virada do avesso, seria um horror para o homem moderno porque "no entendimento positivo do existente, ela inclui ao mesmo tempo o entendimento da sua negação, da sua desaparição inevitável; porque apreende cada forma existente no fluxo do movimento, portanto também com seu lado transitório; porque não se deixa impressionar por nada e é, em

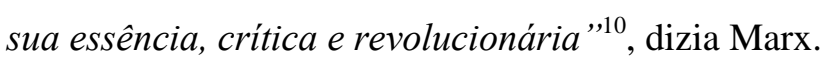

\section{O marxismo brasileiro e sua relação Hegel}

No Brasil, entre os que buscam compreender Marx pela ótica da Ciência da Lógica e da dialética como um método de exposição podemos citar Marcos Lutz Müller, Jorge Grespan e Hector Benoit. Ruy Fausto, ainda que estude largamente $O$ Capital e sua relação com a

\footnotetext{
${ }^{6}$ Karl Marx: Grundrisse - Elementos Fundamentales para la Crítica de la Economía Política 1857-58. Volume I - 16ª Edição. México: Siglo XXI, 1981, p. 22

${ }^{7}$ Vide Hiroshi Uchida: Marx's Grundrisse and Hegel's Logic. USA: Routledge 1988 - Preface.

${ }^{8}$ Karl Marx: O Capital - Posfácio da segunda edição. São Paulo: Nova Cultural, 1988, p. 27.

${ }^{9}$ Karl Marx: $O$ Capital - Posfácio, p. 27.

${ }^{10}$ Karl Marx: O Capital - Posfácio, p. 27.
}

\begin{tabular}{|l|l|l|l|l|}
\hline Qenista Q Dialectus & Ano 3 & n. 8 & Janeiro - Agosto 2016 & p. 60-76 \\
\hline
\end{tabular}


Ciência da Lógica e se ocupe com a chamada crise da dialética e do marxismo, não parece pensar claramente na dialética como um modo de exposição do pensamento ${ }^{11}$.

Para Müller ${ }^{12}$, a dialética na concepção engelsiana se resumiria a uma visão de mundo ou a um tratado sobre o movimento amparado nas três célebres leis elaboradas por Engels: a da unidade e luta dos contrários; a da transformação da quantidade em qualidade e a da negação da negação. Uma concepção assim esquece que na concepção de Marx e Hegel, diz Müller, a dialética era concebida como uma Darstellungsweise, como um modo de exposição.

Müller argumenta que na história da dialética, especialmente nas versões humanistas do marxismo e na versão engelsiana, nenhuma de suas múltiplas dimensões fora tão maltratada e esquecida quanto a noção de exposição (Darstellung).

Segundo suas palavras:

... nenhum dos elementos constitutivos ou dimensões da dialética como método foi tão atingida por esta dissolução teórica e soterrada pelo esquecimento quanto a caracterizada pelo conceito de 'exposição' (Darstellung), que indicava para Hegel e para o Marx d'O Capital a explicitação racional imanente do próprio objeto e a exigência de só nela incluir aquilo que foi adequadamente compreendido. ${ }^{13}$

Para Grespan ${ }^{14}$, no bem conhecido Prefácio d'O Capital Marx estaria falando de duas dialéticas muito distintas e radicalmente opostas entre si. De um lado, teríamos a dialética mistificadora de Hegel que transfigura o real e o sublima. De outro lado, teríamos uma dialética revolucionária que veria em cada forma positiva do existente sua negação e desaparição inevitável.

Segundo uma interpretação bastante popular do marxismo, Marx teria apenas posto a dialética de Hegel de cabeça para cima. Segundo essa concepção, a diferença entre a dialética de Marx e a de Hegel é que a primeira era materialista e a segunda idealista. Uma vez que Hegel havia invertido o mundo e lhe posto de cabeça para baixo, coube a Marx reverte-lo e colocá-lo sobre seus próprios pés. Esta analogia pode ser encontrada no Prefácio onde Marx critica o misticismo da dialética hegeliana. A passagem sempre citada e bastante conhecida está assim em alemão: Sie steht bei ihm auf dem Kopf: É preciso colocá-la de cabeça para cima. Logo

${ }^{11}$ Como o próprio Fausto afirma em sua larga e rica produção, a verdadeira dialética, aquela que se diferencia e se opõe ao discurso da dialética do marxismo vulgar e ao discurso das filosofias do entendimento, seria um discurso rigoroso sobre um objeto constituído de maneira também rigorosa. Ruy Fausto: Lógica e Política - Introdução. São Paulo: Editora Brasiliense, 1983.

${ }_{12}$ Marcos L. Müller: Exposição e método dialético em O Capital. In: Boletim da Sociedade de Estudos e Atividades Filosóficas - Seaf, Belo Horizonte. Volume 2, pp. 15 a 41, 1982.

${ }^{13}$ Müller: Exposição e método dialético em O Capital, p. 17.

${ }^{14}$ Jorge Grespan: A dialética do avesso. In: Revista Crítica Marxista (São Paulo). Volume 14, pp. 26 a 47, 2002.

\begin{tabular}{|l|l|l|l|l|}
\hline Q Rovista Dialectus & Ano 3 & n. 8 & Janeiro - Agosto 2016 & p. 60-76 \\
\hline
\end{tabular}


abaixo dessa mesma passagem, numa passagem também bastante conhecida, Marx comenta que é necessário inverter [umstülpen em alemão] a dialética hegeliana para descobrir o cerne racional dentro de seu envoltório místico.

Grespan comenta, a partir dos estudos de Fulda ${ }^{15}$, que o radical stülpen pode significar na língua alemã o ato de virar do avesso, como quando se arregaça ou se vira do avesso a manga de uma blusa ou a parte interna de uma luva. Inverter, então, teria um significado muito diferente e mais profundo do que o simples ato de virar alguma coisa colocando-a de cabeça para cima. Grespan lembra ainda que o substantivo Stülpe em alemão significa certas partes do vestuário como o cano de uma bota ou de uma luva comprida. Assim, diz Grespan, “a 'inversão’ proposta por Marx pode ser entendida como o ato de virar do avesso, ou melhor, desvirar do avesso algo que estava nesta posição trocada"16. Umstülpen poderia significar, metaforicamente, então, o ato de pôr e virar do lado certo aquilo que estava virado do lado avesso ${ }^{17}$.

Desse modo, segundo Grespan, a diferença entre as duas dialéticas, de Hegel e de Marx, estaria em que "em Hegel a diferença estaria no lado de fora e a identidade no de dentro; enquanto em Marx, ao contrário, a identidade é que aparece no lado de fora, determinada por uma diferença no lado de dentro "18. Assim, para Marx, desmistificar e inverter a dialética hegeliana seria o mesmo que mostrar que a suposta identidade interna não passaria de uma aparência ainda a ser superada, pois por trás das aparentes contradições já resolvidas e superadas pela especulação metafísica de Hegel haveria ainda um universo de contradições reais se desenvolvendo que exigiria uma solução.

Para Benoit, o lado mistificador da dialética de Hegel viria de sua adesão inconsciente à tradição procliana da dialética. Segundo ele "da versão procliana da dialética, Hegel retomará um Platão hipostasiado (construído a partir de uma leitura mística do diálogo Parmênides) e mesclado com a tradição parmenideano-aristotélica" ${ }^{\prime 19}$.

Assim, para Benoit, ainda que em sua maturidade Marx tenha confessado ser um discípulo de Hegel e empregado alguns termos e expressões da terminologia hegeliana em $O$ Capital, não seria possível encontrarmos em Marx e em $O$ Capital uma lógica dialética herdada

\footnotetext{
${ }^{15}$ Grespan refere-se a dois artigos publicados em 1974 no Anuário Hegeliano: Fulda, H. F. - "These zur Dialektik als Darstellungsmethode (im 'Kapital' von Marx)", e também Theunissen, M. - "Krise der Macht. These zur Theorie des dialektischen Widerspruchs”, in Hegel Jahrbuch, Köln, Pahl-Rugenstein Verlag.

${ }^{16}$ Grespan: A dialética do avesso, p. 26.

${ }^{17}$ Lembremos que a palavra um em alemão - seja como preposição, seja como prefixo de outras palavras - também possui o sentido de dar a volta em, ou ainda de virar ou girar em torno de. Umstülpen poderia significar, então, revirar ou desvirar alguma coisa para o seu lado certo.

${ }^{18}$ Grespan: A dialética do avesso, p. 28.

${ }^{19}$ Hector Benoit: Da lógica com um grande L à lógica de O Capital. In: Armando Boito; Caio Navarro de Toledo e outros. (Org.). Marxismo e Ciências Humanas. São Paulo: Xamã, 2003, pp. 15 a 25.
}

\begin{tabular}{|l|l|l|l|l|}
\hline Qenista Q Dialectus & Ano 3 & n. 8 & Janeiro - Agosto 2016 & p. 60-76 \\
\hline
\end{tabular}


diretamente de Hegel. Como diz Benoit, "ainda que Marx dialogue constantemente com a lógica dialética hegeliana, não existe em Marx, propriamente, uma lógica herdada de Hegel "20.

A dialética existente em $O$ Capital, segundo Benoit, não poderia ser, então, a lógica dialética de Hegel. Não poderia ser também a dialética do chamado materialismo dialético das filosofias marxistas inspiradas em Engels, como demonstrou Müller, e na idéia de que a contradição permearia todo o universo dos seres e da natureza. Outra forma, errônea, de conceber a dialética em Marx, segundo Benoit, seria aquela que a considera como uma ontologia. Segundo ele, "o projeto ontológico, que aparece também na filosofia antiga, é diretamente ligado à tradição parmenideana e, assim, à lógica da não-contradição ${ }^{, 21}$. Benoit retoma a história da dialética, desde os gregos até Hegel, para mostrar que uma ontologia, seja ela uma onto-teologia ou mesmo uma ontologia materialista, nunca poderia passar de uma concepção filosófica centrada na hegemonia absoluta do Ser e na lógica da identidade. A concepção de dialética em Marx, segundo Benoit, estaria muito mais próxima da concepção de Platão exposta no diálogo sofista do que nas ontologias de inspiração parmenideana.

Segundo Benoit:

ao demonstrar o ser do não-ser, abria-se no diálogo Sofista o espaço para uma possível lógica da contradição ou lógica dialética. Mas este lógos ali esboçado não seria uma onto-logia, um logos centrado no Ser, no on ou no einai, mas sim, algo como uma koino-logia, ou seja, um lógos do koinón (um lógos do que é comum), um lógos que realiza $o$ transpassamento dos gêneros antagônicos, um lógos da contradição, [um logos que] portanto, arruinaria todo o projeto ontológico. $^{22}$

Por essa noção de dialética como uma koino-logia, como um logos do que é comum a todos os entes e gêneros, torna-se, segundo ele "insustentável uma ontologia dialética marxista, ${ }^{, 23}$.

Benoit, por esses motivos, concorda com Müller acerca do caráter expositivo da dialética em Marx e de sua relação com a chamada Darstellungsweise hegeliana. Conforme suas palavras "a dialética como modo de exposição é a forma, aparentemente mais modesta, mas, ao mesmo tempo, a mais documentada e evidente da dialética em Marx ${ }^{24}$.

\section{O problema da crise e a crítica à noção de absoluto em $O$ Capital}

\footnotetext{
${ }^{20}$ Benoit: Da lógica com um grande L à lógica de O Capital.

${ }^{21}$ Benoit: Da lógica com um grande L à lógica de O Capital.

${ }^{22}$ Benoit: Da lógica com um grande L à lógica de O Capital.

${ }^{23}$ Benoit: Da lógica com um grande L à lógica de O Capital.

${ }^{24}$ Benoit: Da lógica com um grande L à lógica de O Capital.
}

\begin{tabular}{|l|l|l|l|l|}
\hline Q & Dovista \\
\hline
\end{tabular}


Como temos dito, apenas aparentemente podemos considerar as estruturas dialéticas de Hegel e Marx como estruturas homólogas. Se em Hegel todo o processo contraditório das categorias é concluído e resolvido retornando-se constantemente ao ponto de partida positivo, ao princípio positivo da realidade, em Marx o processo contraditório das categorias dirige-se inevitável e necessariamente na direção do futuro, na direção do ponto de rompimento e desestruturação total do sistema - na direção da crise geral e total do sistema. Se em Hegel o resultado final do processo contraditório é resolvido e consumado pelo conceito de Absoluto, em Marx, o resultado final do processo é resolvido e consumado pelo conceito de crise $\mathrm{e}^{25}$.

Ainda que do ponto de vista estrutural a Ciência da Lógica e $O$ Capital possuam uma disposição formal e categorial triádica homóloga, do ponto de vista de seus resultados, porém, não há entre ambas as obras e filósofos nenhuma homologia e relação identitária possível. Em nosso entendimento, como para o entendimento de Hector Benoit, o problema da dialética, do telos e das tendências gerais do sistema capitalista não pode ser, por isso, de modo algum, compreendido a partir do entendimento do telos e do sentido dialético geral da Ciência da Lógica de Hegel pelos motivos que desenvolveremos a seguir.

A realidade em sua determinação última, efetiva e concreta, a realidade tomada enquanto resultado, resultado último construído pela ação do pensamento, já era conhecida por Marx através da dialética de Hegel. Para Hegel, como sabemos, a realidade como resultado se apresentava na forma do Absoluto. $\mathrm{O}$ termo absoluto em filosofia é geralmente empregado para designar coisas como o incondicionado, o não dependente, o não relativo, o que existe em si e para si, o que está livre de toda determinação exterior e contingente, o que é total, completo e perfeito em si mesmo, aquele que é puro e sem misturas que o corrompem, aquele que porque é puro é livre de toda culpa e de todo pecado, aquele que porque não possui mistura com o que lhe corrompe não sofre alterações em sua natureza, aquele que permanece eternamente em seu estado positivo. O termo absoluto pode significar, também, fim, acabamento ou resultado positivo de um processo. Na religião, o termo absoluto é empregado para significar o próprio Deus.

\footnotetext{
${ }^{25}$ Para a compreensão dialética do conceito de crise convidamos o leitor à leitura de nossa obra A questão da crise em $O$ Capital de Marx (Benoit \& Antunes) lançada recentemente (abril/2016) pela Editora Paco Editorial (SP).
}

\begin{tabular}{|l|l|l|l|l|}
\hline Gonista Dialectus & Ano 3 & n. 8 & Janeiro - Agosto 2016 & p. 60-76 \\
\hline
\end{tabular}


Em Hegel, o termo absoluto, além de receber todas estas significações, significa, ainda, o momento do espírito, da síntese e da unidade mediada, da unidade que contém em si o momento do negativo e da diferença, do negativo e da diferença suprassumidos e elevados ao modo da identidade. Em Hegel, o absoluto significa a verdade como totalidade, como contradição resolvida, como unidade da identidade com a diferença, como resultado positivo do movimento dialético das categorias.

O termo absoluto enquanto fim, acabamento ou resultado positivo de um processo possui, também, origem e significado no Direito. Os termos latinos ab-solvo ou ab-solutum podem significar estar livre $d e^{26}$. Nos tribunais, o absolvido é aquele que, depois de lançada sobre ele determinada acusação ou predicado negativo, mediante provas e argumentos lógicos, demonstra racionalmente a falsidade da acusação e da negatividade que lhe são imputadas.

O absolvido é aquele que, mediante rigorosa e trabalhosa demonstração racional, se mostra, ao final do processo acusatório, estar livre de toda impureza, de toda infâmia, de toda culpa, de todo pecado, de toda particularidade e de toda negatividade e corrupção, retornando, assim, ao estado positivo originário, ao princípio ou momento que antecede imediatamente o começo do processo acusatório.

A declaração de pureza e inocência emitida pelo juiz suprime e resolve todas as críticas e acusações, toda a negatividade, lançadas contra o acusado. Ao final do processo acusatório, ao final do julgamento, ao final do juízo, o absoluto retorna,

\footnotetext{
${ }^{26}$ Vide Lewis \& Short: A Latin Dictionary - Perseus Digital Library. Lewis e Short listam, entre muitos outros, os seguintes empregos e significados dos termos absolvo e absolutum na língua latina: 1) To free from (Ciceronian): ut nec Roscium stipulatione alliget, neque a Fannio judicio se absolvat, extricate or free himself from a lawsuit, Cic. Rosc. Com. 12: "longo bello," Tac. A. 4, 23: caede hostis se absolvere, to absolve or clear one's self by murdering an enemy, id. G. 31.-With gen.: "tutelae," Dig. 4, 8, 3; hence. In judicial lang., t. t., to absolve from a charge, to acquit, declare innocent; constr. absol., with abl., gen., or de (Zumpt, § 446; "ㅅudd. 2, 164 sq.): bis absolutus," Cic. Pis. 39: "regni suspicione," Liv. 2, 8: judex absolvit injuriarum eum, Auct. ad Her. 2, 13; so Cic. Verr. 2, 1,29 al.: "de praevaricatione absolutus," id. Q. Fr. 2, 16.-In Verr. 2, 2, 8, § 22: hic (Dionem) Veneri absolvit, sibi condemnat, are dativi commodi: from the obligation to Venus he absolves him, but condemns him to discharge that to himself (Verres).With an abstract noun: fidem absolvit, he acquitted them of their fidelity (to Otho), pardoned it, Tac. H. 2 , 60. 2) In rhet. lang., unrestricted, unconditional, absolute: "hoc mihi videor videre, esse quasdam cum adjunctione necessitudines, quasdam simplices et absolutas," Cic. Inv. 2, 57, 170. 2) In gram. a) Nomen absolutum, which gives a complete sense without any thing annexed, e. g.: "deus," Prisc. p. 581 P. b) Verbum absolutum, in Prisc. p. 795 P. that has no case with it; in Diom. p. 333 P., opp. inchoativum. c) Adjectivum absolutum, which stands in the positive, Quint. 9, 3, 19.-Adv.: absŏlūtēe , fully, perfectly, completely (syn. perfecte), distinctly, unrestrictedly, absolutely, Cic. Tusc. 4, 17, 38; 5, 18, 53; id. Fin. 3 , 7. 26; id. Top. 8, 34 al.-Comp., Macr. Somn. Scip. 2, 15. (http://www.perseus.tufts.edu/hopper/text?doc=Perseus:text:1999.04.0059:entry=absolvo).
}

\begin{tabular}{|l|l|l|l|l|}
\hline Q & Dovista \\
\hline
\end{tabular}


assim, ao seu estado de dormência e quietude original onde supera todas as críticas e predicados negativos que o retiravam de sua sublime e perfeita identidade.

Em Hegel, além dos significados acima mencionados, o absoluto possui também este significado jurídico, sendo aquele que durante o longo processo dialético produz e acolhe o negativo para, logo em seguida, através da síntese e do caminho de volta em direção ao princípio originário de todo o processo, da unidade e da identidade, negá-lo, através da negação da negação, restaurando e devolvendo ao processo toda a positividade tomada desde o começo como ponto de partida.

Em Hegel, a negação e a diferença têm sua origem, sua vida e existência no próprio absoluto, sendo meros momentos, instrumentos, pontos de passagem e de desenvolvimento da identidade e da unidade. Nele predominam inteiramente o absoluto enquanto princípio e resultado e a positividade total do processo. O absoluto, o totalmente idêntico a si mesmo, está inteiramente presente no começo enquanto princípio, no fim enquanto retorno e resultado e no completo desenrolar de suas mediações.

Ao contrário de Hegel, em Marx domina totalmente o princípio da negatividade e da oposição. Para Marx, a negação da negação deve ser concebida não como a restauração dialética da positividade inicialmente posta como princípio, mas, sim, como a negatividade total e verdadeira do processo, como abolição e supressão real, e não meramente ideal, das contradições. Em Hegel, a negação da negação é positividade, purificação e sublimação da realidade posta. Hegel, por essa paixão incontida pelo positivo, pelo retorno do negativo e da diferença ao absoluto, fora, justamente, chamado por Feuerbach de o Próclus da Alemanha ${ }^{27}$.

Em Marx, ao contrário, a solução das contradições não é simplesmente dialética, mas, sobretudo, revolucionária. A suprassunção marxiana não é, como em Hegel, elevação e conservação do negativo e da diferença no positivo e na identidade mediante retorno ao ponto de partida originário, ao positivo e à identidade postos no princípio, como princípio, mas sim, aniquilação da realidade através do labor infatigável do negativo. Em Marx, a negação da negação é a crise, é a aniquilação, a destruição e abolição total da realidade, é o afundamento e a corrupção inevitável, sem restauração ou retorno cristão-procliano, do positivo no negativo.

27 Vide Isabelle Garo: La représentation chez Feuerbach: sensation, religion et philosophie. France: Archives de Philosophie. 2001/4 (Tome 64). Pages 669 à 693.

\begin{tabular}{|c|c|c|c|c|}
\hline QRovista Dialectus & Ano 3 & n. 8 & Janeiro - Agosto 2016 & p. $60-76$ \\
\hline
\end{tabular}


Em grego clássico, onde Marx certamente se inspirou, a palavra krisis

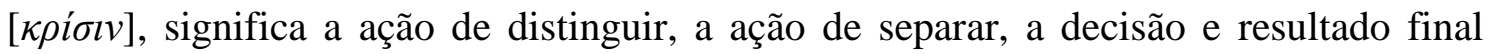
negativo de um processo. Em Heródoto e Xenofonte, por exemplo ${ }^{28}$, krisis tem o significado jurídico de uma condenação, onde o resultado do processo se mostra totalmente negativo e desfavorável ao acusado. No Evangelho de Mateus [10.15], por exemplo, o Dia do Julgamento, o Dia do Juízo Final, aparece como o Dia da Crise

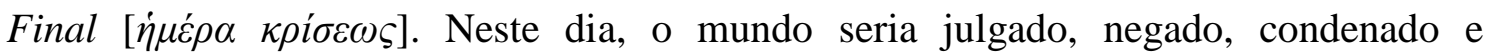
totalmente abolido pelas suas oposições e contradições jamais resolvidas.

Para Marx, o conceito de crise é inseparável do próprio conceito de capital e o estudo de um implica necessariamente no estudo do outro. Uma análise dialética do conceito de crise deve se desenvolver, portanto, simultaneamente com a análise e desenvolvimento do conceito de capital. A obra $O$ Capital, como sabemos, tem como meta expor o conceito de capital, o fundamento da sociedade burguesa. Exposição que se eleva do concreto (pressuposto) ao abstrato que retorna ao concreto (posto), ao concreto enquanto concreto desenvolvido e exposto pela lexis e pelo pensamento. Assim, no trajeto expositivo dos três livros de $O$ Capital, ressaltamos, desde já, quatro questões fundamentais para o entendimento do conceito de crise como resultado negativo de um processo.

Primeira questão: os Livros Primeiro e Segundo possuem como objeto o conceito mais genérico e mais abstrato de certos momentos do movimento do capital. Nestes livros, vemos o movimento do conceito de capital em suas formas mais puras, o conceito de capital enquanto tal, sem consideração por suas formas derivadas como o capital produtivo, comercial e a juros (todas elas formas derivadas do capital-industrial, a forma mais pura e abstrata, mas, ao mesmo tempo, mais fundamental do capital). Estes Livros não possuem como objeto, portanto, as leis e contradições do capital em sua atualidade (enérgeia), mas as leis e contradições do capital em suas formas

\footnotetext{
${ }^{28}$ Vide Liddel \& Scott Greek-English Lexicon - Perseus Digital Library. Liddel e Scott listam, entre muitos outros, os seguintes empregos e significados gregos do termo Krisis: 1) separating, distinguishing,

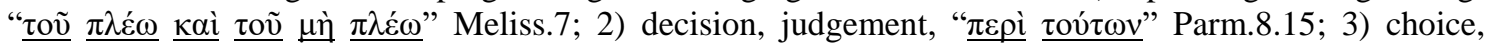

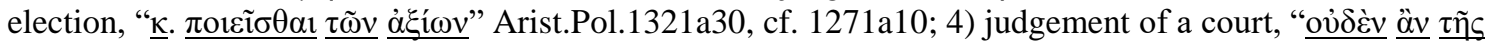

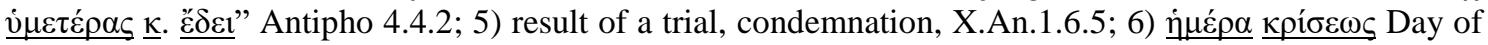

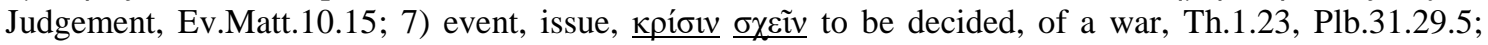

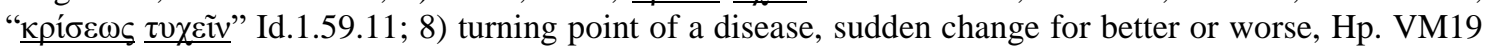
(pl.),

Gal.9.550. (http://www.perseus.tufts.edu/hopper/morph?l=kri\%2Fsis\&la=greek\&can=kri\%2Fsis0\#lexicon).
}

\begin{tabular}{|l|l|l|l|l|}
\hline Q Ronista Dialectus & Ano 3 & n. 8 & Janeiro - Agosto 2016 & p. 60-76 \\
\hline
\end{tabular}


potenciais (como dynamis). O capital e a sociedade capitalista em sua configuração mais real e concreta são analisados somente no Livro Terceiro. Ainda que, desde o primeiro capítulo do Livro Primeiro, seguindo um movimento em espiral, as formas abstratas vão sendo superadas, gradualmente, e retomadas em formas cada vez mais determinadas. O Livro Primeiro, por exemplo, como totalidade própria, contém abstratamente todo o movimento dos três livros: a forma mercadoria, a circulação, a produção de mais-valia, a acumulação de capital, e a superação do capital com a expropriação dos expropriadores (cap. XXIV). Já o Livro Segundo recomeça o movimento novamente da circulação, mas agora, a mercadoria inicial, com as determinações conquistadas no Livro Primeiro, desde o início é M', ou seja, contém a extração de mais-valia e, assim, todas as contradições expostas no Livro Primeiro. O Livro Terceiro continuará a ampliação em espiral dos dois livros anteriores tentando realizar a síntese negativa final.

Somente no Livro Terceiro a sociedade capitalista será concebida, portanto, com todas as suas determinações, sobretudo, com aquelas provocadas pela pluralidade de capitais e pela concorrência. Os Livros Primeiro e Segundo são livros mais abstratos exatamente porque neles colocam-se entre parênteses, em grande parte, a pluralidade de capitais e a concorrência. A luta entre os diversos capitais individuais que reciprocamente se odeiam não aparece de forma mais desenvolvida antes do Livro III, apesar de que já é mencionada mesmo no Livro I. Porém, postas a pluralidade de capitais e a concorrência de forma desenvolvida no Livro Terceiro, a exposição sobre o conceito de capital passa, então, aqui, a possuir todas as determinações na sua forma plena.

Segunda questão: nos Livros Primeiro e Segundo analisa-se, particularmente, o conceito de crise também de modo mais puro e abstrato. As muitas contradições que remetem ao conceito de crise, que já aparecem nesses livros, mostramse como contradições ainda bastante formais, potenciais e abstratas. A crise se converte em realidade plena somente no Livro Terceiro, porque somente ali serão postas de forma desenvolvida a pluralidade de capitais e a concorrência. Seriam postas ainda, de forma plenamente desenvolvida, também as classes sociais, objeto do capítulo LII, do qual, infelizmente, só temos algumas linhas.

Terceira questão: nos dois primeiros livros a concorrência foi abstraída da exposição exatamente porque ela não funda as leis e tendências gerais da sociedade

\begin{tabular}{|l|l|l|l|l|}
\hline Qonista Dialectus & Ano 3 & n. 8 & Janeiro - Agosto 2016 & p. 60-76 \\
\hline
\end{tabular}


capitalista, a concorrência apenas converte essas leis em realidade. A concorrência, para Marx, é sempre fonte de perturbação e engano para o pensamento e, por isso, para apreendermos o conceito de capital em sua imanência é necessária sua abstração.

Quarta questão: no Livro Primeiro analisa-se de modo formal e abstrato as leis da produção da mais-valia enquanto tal, da mais-valia em seu nível mais puro e idealizado. No Livro Segundo analisa-se, do mesmo modo formal e abstrato, as condições puras e idealizadas para a realização da mais-valia global, ainda que esta já esteja posta mais abstratamente desde o início pelo Livro Primeiro. No Livro Terceiro analisa-se a distribuição desta mais-valia global já produzida e realizada entre a pluralidade dos capitais individuais.

Assim, uma exposição dialética do conceito de crise como resultado negativo de um processo deve ser dividida em três grandes momentos. No primeiro momento se abrange a exposição das contradições mais genéricas e potenciais contidas no Livro Primeiro, onde se realiza uma primeira totalização abstrata da produção capitalista, desde a sua forma elementar, a mercadoria, até a sua destruição, a negação da negação.

Neste primeiro momento surge, assim, diz Marx, a possibilidade de crises [Möglichkeit der Krisen], cujo desenvolvimento até sua realidade [Wirklichkeit] exige todo um conjunto de condições que será preenchido somente ao final do processo expositivo, quando a crise se mostrará em toda a sua negatividade e realidade. Neste primeiro momento, surge apenas a possibilidade geral e abstrata da crise [Allgemeine, abstrakte Möglichkeit der Krise], diz Marx, surge apenas a forma mais abstrata da crise, sem conteúdo e o impulso pertinente a esse conteúdo. A crise surge no começo de $O$ Capital em sua potencialidade [Krise potentia] e não ainda em sua realidade [Wirklichkeit]. Na medida, porém, em que a exposição do conceito de crise ao longo dos três tomos de $O$ Capital for se desenvolvendo e negando tais abstrações, pondo em seu lugar as condições mais determinadas da produção capitalista, as classes sociais e as contradições entre elas, a possibilidade abstrata da crise vai, então, ao mesmo tempo, se convertendo em realidade ${ }^{29}$.

No segundo momento, no Livro Segundo, se realiza a exposição das contradições potenciais contidas na circulação, porém, já com as determinações obtidas

\footnotetext{
${ }^{29}$ Vide: O Capital. Livro Primeiro - Volume I, p. 99. MEW 23, p. 128. Teorias da Mais-valia. Volume II. S.P: Difel, 1980, p. 945. MEW 26.2, p. 510.
}

\begin{tabular}{|c|c|c|c|}
\hline Qevista Dialectus & Ano 3 & n. 8 & Janeiro - Agosto 2016 \\
\hline
\end{tabular}


no Livro Primeiro. Por isso, parte-se não mais da forma simples da mercadoria, mas sim, da sua forma capitalista supondo, portanto, a mais-valia (M'). Todo o processo contraditório é exposto, contudo, ainda com a abstração da concorrência.

No terceiro grande momento, formado pelo Livro Terceiro, produção (Livro Primeiro) e circulação (Livro Segundo) finalmente são unificadas e se analisa a conversão em realidade de todas as contradições descritas anteriormente, porém, submetidas agora à existência da pluralidade de capitais e da concorrência. O Livro Terceiro, como sabemos, tem exatamente como subtítulo $O$ processo total da produção capitalista (Der Gesamtprozess der kapitalistischen Produktion), isto é, trata-se ali da síntese dos resultados obtidos nos dois primeiros livros agora transformados pelas determinações da concorrência entre os capitais.

O processo de desenvolvimento da crise, o de conversão de sua possibilidade formal e abstrata em realidade, é o mesmo processo que concretiza todas as contradições mais simples e abstratas do capital, mostrando-as, finalmente, como luta de classes, expropriação dos expropriadores, negação da negação, superação do modo de produção capitalista e, assim, último e derradeiro desenvolvimento da teoria marxista da crise. Somente partindo desta concepção dialética de exposição, podemos desvelar, então, como se desenvolve, de forma mais detalhada, o conceito de crise como negação da negação ao longo dos três livros de $O$ Capital. Conceito que desemboca necessariamente na negação da negação, no colapso e crise geral inevitável, mais cedo ou mais tarde, do sistema capitalista como um todo, pelas suas contradições fundamentais: as contradições da luta de classes.

Enquanto para Hegel, o resultado final do processo na figura do absoluto se mostra inteiramente positivo e vitorioso para o acusado, para os gregos, nos quais Marx se inspira, o resultado na forma da krise se mostra inteiramente negativo e favorável à acusação. Enquanto na noção de absoluto como resultado a negatividade do processo é derrotada e anulada pela sentença favorável ao acusado, que retorna e restaura o estado positivo anterior ao processo, na noção de krise não há retorno e restauração da situação positiva original. Na krise como resultado negativo e necessário, domina totalmente o princípio da oposição, da negação e da condenação da suposta unidade e identidade absolutas do acusado.

Na noção de krise domina, portanto, o princípio verdadeiramente dialético da negação da negação, da negação como condenação e prova da necessidade do

\begin{tabular}{|c|c|c|c|c|}
\hline Q Rovista Dialectus & Ano 3 & n. 8 & Janeiro - Agosto 2016 & p. $60-76$ \\
\hline
\end{tabular}


condenado ser abolido da realidade. Na noção de krise como resultado, o princípio da negatividade derrota, anula e afunda totalmente, portanto, a positividade do processo, impulsionando o movimento de crítica para frente, sem jamais restaurar e retornar ao seu ponto de partida positivo original.

Em $O$ Capital, a crise enquanto resultado negativo e necessário do processo aparece como a própria negação da negação, como a verdadeira negatividade do processo, como a destruição e derrocada total do sistema capitalista pelo desenvolvimento e aprofundamento de suas próprias contradições não resolvidas, pela elevação da classe operária ao plano da luta revolucionária pelo poder, pela expropriação dos expropriadores, pelo fim da propriedade privada, do mercado, da mercadoria e do dinheiro, pela organização consciente e racional da vida econômica e, por fim, pela fundação de um novo modo de vida e de um novo futuro para a humanidade.

Pensamos que somente deste modo, partindo do conceito de crise como resultado negativo e necessário, da crise como o estremecer e o abalar total da realidade posta, da crise como o despedaçar e o desmoronar total desta realidade, da crise como marcha e abertura de caminho para o futuro, podemos compreender, então, a profunda, radical e inconciliável diferença entre os sistemas dialéticos de Marx e Hegel.

\section{Referências}

ARTHUR, Christopher J.The Myth of 'Simple Commodity Production'. In: Marx Myths and Legends, 2005. Disponível no website http://marxmyths.org. Tradução para o português pode ser encontrada no website https://jadirantunes.wordpress.com/resenhas/.

BENOIT, Hector Benoit: Da lógica com um grande $\mathbf{L}$ à lógica de $\mathbf{O}$ Capital. In: Armando Boito; Caio Navarro de Toledo e outros. (Org.). Marxismo e Ciências Humanas. São Paulo: Xamã, 2003, pp. 15 a 25.

FAUSTO, Ruy. Lógica e Política. Introdução. São Paulo: Editora Brasiliense, 1983.

GARO, Isabelle: La représentation chez Feuerbach: sensation, religion et philosophie. France: Archives de Philosophie. 2001/4 (Tome 64). Pages 669 à 693.

GRESPAN, Jorge. A dialética do avesso. In: Revista Crítica Marxista (São Paulo). Volume 14, pp. 26 a 47, 2002.

\begin{tabular}{|c|c|c|c|c|}
\hline Rovita Dialeatus & Ano 3 & n. 8 & Janeiro - Agosto 2016 & p. $60-76$ \\
\hline
\end{tabular}


LEWIS \& SHORT: A Latin Dictionary. Perseus Digital Library. (http://www.perseus.tufts.edu/hopper/text?doc=Perseus:text:1999.04.0059:entry=absolv o).

LIDDEL \& SCOTT. Greek-English Lexicon. Perseus Digital Library. (http://www.perseus.tufts.edu/hopper/morph?l=kri\%2Fsis\&la=greek\&can=kri\%2Fsis0\# lexicon).

MARX, Karl. Grundrisse - Elementos Fundamentales para la Crítica de la Economía Política 1857-58. Volume I - 16ª Edição. México: Siglo XXI, 1981.

1988.

O Capital. Posfácio da Segunda Edição. São Paulo: Nova Cultural,

MEANEY, Mark. Capital as Organic Unity: The Role of Hegel's Science of Logic in Marx's Grundrisse. Congrès Marx international IV. Paris 2004. (http://netx.uparis10.fr/actuelmarx/m4meaney.htm).

MÜLLER, Marcos L. Exposição e método dialético em O Capital. In: Boletim da Sociedade de Estudos e Atividades Filosóficas - Seaf, Belo Horizonte. Volume 2, pp. 15 a $41,1982$.

ROSDOLSKY, Roman. Génesis y Estructura de El Capital de Marx: estudios sobre los Grundrisse. Quinta Edição. México: Siglo Veintiuno Editores, 1986.

UCHIDA, Hiroshi. Marx's Grundrisse and Hegel's Logic. USA: Routledge 1988 Preface. Disponível em http://www.marxists.org/subject/japan/uchida/index.htm.

\begin{tabular}{|c|c|c|c|c|}
\hline Renista Dialeatus & Ano 3 & n. 8 & Janeiro - Agosto 2016 & p. $60-76$ \\
\hline
\end{tabular}

